\title{
Conceptualizing a Theoretical Framework: Embodied Narrative Knowing
}

\section{Overton, Michael Duncan}

University of Tennessee, Knoxville USA.

\begin{abstract}
The dominant Western epistemological and ontological perspective marginalizes "other ways of knowing” (Taylor, 1997) that adult learners use to make meaning of their experiences (Crossley, 2007; and Michelson, 1998). Other ways of knowing have also been called non-Western perspectives and are defined as having their "roots in cultures and...traditions that pre-date Western colonization, modernization, and Western-driven globalization (Merriam, 2007, p. 173). The aim of this work is to explore support for a theoretical framework, informed by three established paradigms, to conceptualize non-Western and other ways of knowing. This work outlines the three paradigms that are utilized: Social Constructivism, Embodied Knowing, and Narrative Knowing. This work re-presents an experience of an adult learner who practices the martial arts (a traditionally non-Western practice) in order to offer preliminary validation and show a need for embodied narrative knowing as a theoretical framework for understanding non-Western ways of knowing.
\end{abstract}

Keywords: Embodiment; Narrative; Martial Arts; Non-Western 


\section{Introduction}

As adults, how do we learn? In the West, learning is often perceived as being acquired through formal schooling methods, in which knowledge is validated through rigorous scientific research and empirical evidence (Merriam \& Associates, 2007). This Western paradigm is largely influenced by Cartesian dualism, which promotes a mind/body separation, and values the cognitive and rational mind above all else (Merriam \& Associates, 2007; Michelson, 1998). Dominant Western perspectives marginalize "other ways of knowing" (Taylor, 1997) that adult learners use to make meaning of their experiences (Crossley, 2007; and Michelson, 1998). Other ways of knowing that have been conceptualized in literature are: creativity, intuition, empathy, emotion, affective learning, the guiding force of feelings, spiritual dimensions, relationships, role of context, somatic, whole person and embodiment (Taylor, 1997).

In the modern era the field of Western adult education has been shifting toward a global focus, retraining adult learners and educating for global competencies (Merriam \& Brockett, 2007). In order to facilitate this new direction in adult learning and education strategies, an understanding of non-Western perspectives on the foundations of adult learning and education within the ever expanding global community is needed (Merriam, 2007). Non-Western perspectives are defined as having their "roots in cultures and...traditions that pre-date Western colonization, modernization, and Western-driven globalization (Merriam, 2007, p. 173). In higher education settings the need to reach a more diverse student population is more present than ever. With the increase of international students in the higher education landscape and the shrinking of global distances, through such tools as the internet, a one-size-fits-all model of education favored as a dominant standard in Western higher education is no longer adequate to meet the needs of these students.

As of this writing there is no theoretical framework readily available to Western audiences to assist in the understanding and framing of non-Western ways of knowing as a whole. This article proposes a theoretical framework, embodied narrative knowing, that is designed to address this deficiency. This framework is informed by three established paradigms which are integrated to create this framework: 1) Embodiment (Brown \& Johnson, 2000; and Freiler, 2008); 2) Social constructivism (Berger \& Luckmann, 1966; and Merriam \& Brockett, 2007); and 3) Narrative knowing (Clandinin \& Connelly, 2000; and Polkinghorne, 1995). This article will unpack the three paradigms and show how they are able to integrate into one theoretical framework. A brief example from a transcript collected through work from the author's dissertation will illustrate how the practice of a nonWestern way of knowing (i.e., martial arts) supports the need for this theoretical framework. 


\section{Need for a Framework}

The need for a theoretical framework to specifically address a non-Western way of knowing stems from a lack of understanding, in Western hegemonic practices, of other ways of knowing. Gut feelings, intuition, instinct, and wisdom are all considered other ways of knowing and have been explored by researchers as individual constructs in relation to the meaning making process (Taylor, 1997, and Merriam, 2007). However, no theoretical framework exists, that allows other ways of knowing to remain a central focus of study, or allows for a better understanding by Western audiences. Instead other ways of knowing are being subsumed under pre-established frameworks, such as Transformative Learning theory (Taylor, 1997) and others.

The rationale for choosing the three paradigms to support this framework stem from the different ways that each paradigm interact and support each other in building a foundation to explore other ways of knowing. Specifically, the key component that each of these paradigms shares in the role of experience as central to their ontological and epistemological understandings of truth and the nature of reality. Each of these paradigms are discussed and a visual model has been provided to assist in the understanding of this theoretical framework in figure 1 .

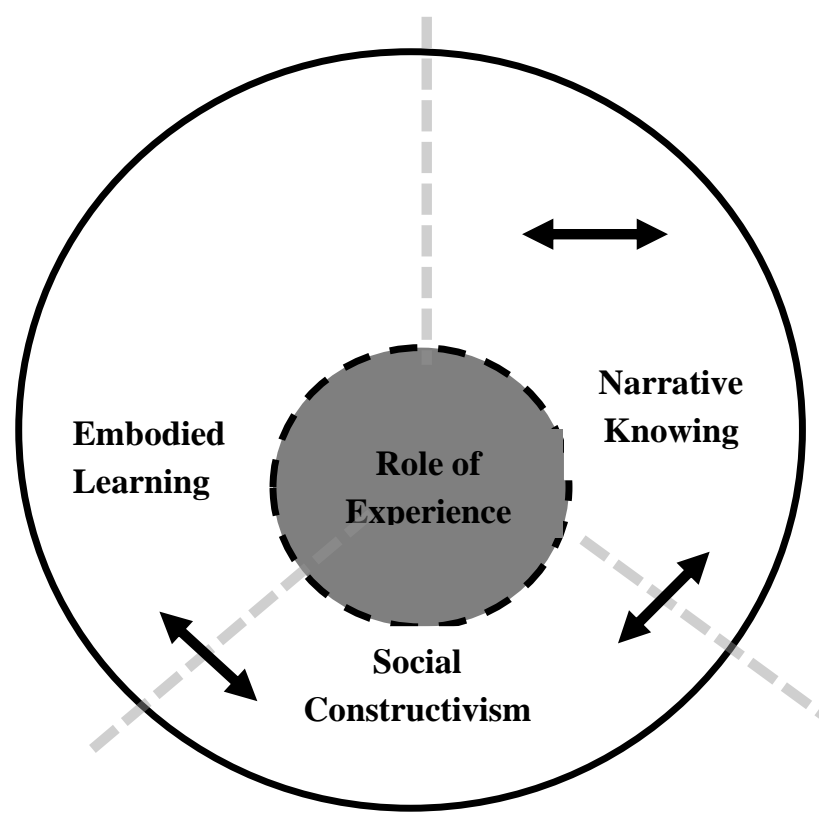




\section{Embodiment}

Embodied learning and knowing incorporates the mind, body, and spirit into the meaning making process (Brown \& Johnson, 2000). This other way of knowing (Taylor, 1997) challenges the dominant hegemony of Western ontological and epistemological perspectives of how we come to be and make meaning of our experiences. There are two parts of embodiment that need to be unpacked for this model. The first is somatic learning and the second is embodied learning and knowing.

\subsection{Somatic Learning}

The most comprehensive conceptualization of somatic learning comes from Amann (2003). Amann (2003) conceptualizes the movement of the body as requiring four distinct contextual interactions to be involved in the meaning making process: kinesthetic learning, sensory learning, affective learning, and spiritual learning. Amann (2003) conceptualizes kinesthetic learning "as a result of the concerted movements of muscles, tendons, and joints" (Amann, 2003, p. 3). The acts of walking, running, jumping, or throwing illustrates the mode of kinesthetic learning that comprises Amann's definition of somatic learning.

The second interaction of the body Amann recognizes is sensory learning. Sensory learning utilizes our five senses for the construction of knowledge in the meaning making process (Amann, 2003). The five senses of sight, smell, hearing, taste, and touch, work in conjunction to define how our bodies make meaning through a somatic lens.

Affective learning is the third interactional factor believed to be "the acquisition of knowledge as a result of paying attention to and honoring our feelings and emotions" (p. 4). The colloquial expression of a "gut feeling" may be the simplest way to understand this type of learning. Affective learning encompasses the concept of self-awareness which requires the recognition of the impact of emotions on our lives (Amann, 2003).

Finally, spiritual learning integrates the three other concepts into a holistic model for learning. Amann (2003) believes that spiritual learning is "about making meaning of our lives" (p. 4) through the construction of knowledge carried out through symbolic gestures such as art, music, rituals, and movements that have particular meanings (Amann, 2003).

Amann's (2003) model "posits that meaning making is created by the body through movement" (p. 5) within each of the learning types. This model of somatic ways of knowing focuses on a different type of learning experience, one that engages the whole person in the learning process. 


\subsection{Embodied Learning}

The second term to tackle is embodied learning, also called embodied knowing or embodiment. Ghane and Sweeny (2013) address the term of embodiment as a catchall for theories and studies that are informed by "basic principles of embodied cognition" (Ghane $\&$ Sweeny, 2013, p. 161). These principles hold that people "perceive their environment in terms of how they can physically interact and perform actions to manipulate objects that surround them" (Gibson \& Walker, 1984 as cited in Ghane \& Sweeny, 2013, p. 161). Thus, embodiment incorporates the behaviors of the mind and body through cognition, affect, and behavior as they interact with the environment.

Freiler (2008) addresses the distinction between somatics and embodiment by stating that they "are all closely aligned and used interchangeably" (Freiler, 2008, p. 39). A common thread that ties them together comes from Freiler's (2008) review of literature in which embodied learning and somatic learning "are associated with an evolving awareness of bodily experiences as a source of constructing knowledge through engaged, lived body experiences of physicality, sensing, and being in both body and world" (p. 39).

Freiler (2008) makes a distinction that "somatic learning generally refers to learning directly experienced through bodily awareness and sensation during purposive bodycentered movements" (p. 39). She goes on to state that "embodiment and embodied learning generally refer to a broader, more holistic view of constructing knowledge that engaged the body as a site of learning, usually in connection with other domains of knowing (for example, spiritual, affective, symbolic, cultural, rational)" (p. 39).

Freiler (2008) views embodiment as a way to conceptualize the construction of knowledge "by incorporating unity of mind and body in the process of knowing through both objective and subjective realms of knowledge construction" (p. 40). These two realms, objective and subjective, represent rational external knowledge construction and internal "personal ways" of knowledge construction respectively (Freiler, 2008). Important to both Amann (2003) and Freiler's (2008) concepts are a unity of both mind and body, not a separation. Their models and concepts neither rank one above the other, instead they require a "remembering" (Michelson, 1998) of both in order to create a more holistic learning experience.

\section{Social Constructivism}

The constructivist paradigm is not a single unified paradigm, but a conglomeration of related ontological and epistemological perspectives that share an underlying commonality. This commonality "is the notion that reality can be known only subjectively...Knowledge is the meaning that people make out of their experiences" (Merriam \& Brockett, 2007). 
The multiple strands of the constructivist paradigm muddy the waters for beginning researchers wishing to rely on this approach. In order to establish a firm base to build this theoretical framework from, a re-tracing of the origins of the social constructivist paradigm is necessary. Flick (2014) and other authors of works on social constructivism cite Schutz (1962), Berger and Luckmann (1966), and Gergen (1995) as foundational for the tradition of social constructivism. Flick (2014), also states that these approaches emphasize "inquiries after the social conventions, perception, and knowledge in everyday life" (Flick, 2014, p. 76).

The conceptualization of social constructivism that informs this model relies primarily on the work of Berger and Luckmann (1966). Berger and Luckmann (1966) are sociologists who closely aligned with a sociological school of thought known as sociology of knowledge. This tradition draws heavily from sociologists such as Marx, Nietzsche, Shuler, Manheim, Durkheim, and Weber. Berger and Luckmann (1966) believe that "the sociology of knowledge, therefore, must concern itself with the social construction of reality" (p. 14). Their process recognizes a Marxian conception that "man's consciousness is determined by his social being" (p. 5), and that human thought is founded in human activity (agency and action) and in the social relations brought about by this activity. This foundation illustrates that there is a relationship between human thought and underlying reality(s) that are manifested in other ways than cognition.

Berger and Luckmann (1966) integrate historicism into their process, to give an "overwhelming sense of the relativity of all perspectives on human events, that is, of the inevitable historicity of human thought" (p. 6). Simply put, all situations (e.g., experiences) can only be understood in their own terms or socio-historical contexts. This lead Berger and Luckmann (1966) to state that "society determines the presence...but not the nature... of ideas" (p. 7); which parallels work by Karl Manheim, that human thought is not immune to the influences of society and "knowledge must always be knowledge from a certain position" (p. 9).

Berger and Luckmann (1966) incorporate sociological perspectives from Schutz (1962) who is "concentrated on the structure of the commonsense world of everyday life" (Berger \& Luckmann, 1966, p. 14). They draw inspiration from Durkheim and Weber defining everyday life as that which "presents itself as a reality interpreted by men and subjectively meaningful to them as a coherent world...It is a world that originates in their thoughts and actions, and is maintained as real by these" (p. 20). Berger and Luckmann (1966) define social construction as a "systematic theoretical reasoning" (p. 12), an "adequate understanding of the 'reality sui generis' of society [which] requires an inquiry into the manner in which this reality is constructed" (p. 16). 
From the social constructivist paradigm, we come to know what is real through our shared interaction with the environment and the others who share that environment with us, at different moments in our time. Lincoln, Lynham, and Guba (2011) believe that "a goodly portion of social phenomena consists of the meaning-making activities of groups and individuals around those phenomena...it is the meaning-making, sense-making, attributional activities that shape action (or inaction)" (Lincoln, Lynham, and Guba, 2011, p. 116). Flick (2014) states that "knowledge is constructed in processes of social interchange; it is based on the role of language in such relationships; and, above all, it has social functions" (Flick, 2014, p. 78). In a social constructivist paradigm, the focus on language within social relationships and the experiences derived from these interactions is a crucial component of the theoretical framework.

\section{Narrative Inquiry/Knowing}

Narrative Inquiry is an increasingly popular methodology of qualitative research, and is acknowledged by a growing number of scholars in many diverse fields such as psychology, literature, anthropology, sociology, history, and education (Roberts \& Shenhav, 2014).

\subsection{Narrative Inquiry as Theory}

As theory, Polkinghorne (1995) tells us that, "[N]arrative inquiry refers to a subset of qualitative research designs in which stories are used to describe human action" (Polkinghorne, 1995, p. 5). The terminology and meanings of narrative are diverse, and vary from one research project to another. A unique language emerges that narrative researchers rely on but do not always agree upon (Spector-Mersel, 2010). This unique language comes with baggage in the form of 2 concepts: (1) the interchangeability of story and narrative, and (2) the co-constructed nature of narratives.

Story. A unique element of narrative inquiry is the use of participant's narratives or stories (Clandinin \& Connelly, 2000; and Polkinghorne, 1995). Narrative Inquiry "is the understanding that narrative is a way of knowing" (Kramp, 2004, p. 106) and that this knowing is expressed in stories. According to Kramp (2004) "each story has a plot...reflects the perspective of the narrator...has a setting in time and place...has a beginning, middle, and ending, although not necessarily presented in that order as it is told" (Kramp, 2004, p. 109). Bruner (1996) states that, at minimum, a story has a character who acts to achieve a goal (plot) in a context by use of certain means.

Polkinghorne (1995) uses the term story to "signify narratives that combine a succession of incidents into a unified episode" (p. 7). Drawing primarily upon the linguistic research of Bruner, Ricoeur, and others, Polkinghorne (1995) establishes his definition of story, in which plot plays an integral part. Plot arranges the story into a narrative structure that: sets 
a temporal range; criteria for selecting events to be included; temporally ordering the events; and making meaning of the events in relation to the story as a unified whole.

Clandinin and Connelly (2000) conceptualize stories as being within a "three-dimensional space", which includes "personal and social (interaction); past, present, and future (continuity); combined with the notion of place (situation)" (Clandinin and Connelly, 2000, p. 50). This framework situates stories in time, paying attention to how this temporality affects the telling and retelling of the story. The three-dimensional space brings in the personal and social dimensions of stories and situates story, and telling of story, within specific places or sequences.

Co-construction. A story is co-constructed because there is a teller and a listener. Stories carry weight, are often purposeful, and convey meaning through the interaction of the teller and audience, or the co-constructed tellings and re-tellings (Clandinin \& Connelly, 2000). 'Narrative inquiry assumes 'personal involvement' as the very condition that makes it possible for you, as researcher to gather and interpret narratives" (Kramp, 2004, p. 114). Qualitative research requires the researcher to act as instrument for data collection, making personal involvement inescapable (Merriam, 1995). Instead of "dispassionately chronicling experience and events" (Kramp, 2004, p. 114), the co-construction of narratives brings the researcher into relationship with the story being co-constructed with the participant as insider and outsider.

\section{Example}

The example provided comes from an interview conducted by the author as requirement of completion for his dissertation.

"[B]alancing those three pieces you know, making sure that you know physically you work on it, mentally you prepare and then spiritually you invest in it. Putting those three pieces together is really important because that to me is what gives you the benefits beyond what happens you know for that one hour class. And then it's taking that and living with it in that day to day. Using whatever you've learned to teach others and help other people out." (Interview Transcript from dissertation in progress)

This excerpt re-tells one participant's philosophy of their practice of the martial arts. In this example the use of the embodied narrative knowing theoretical framework allows the participant's entire story to be kept intact including the nature of interactions, interplay of mind and body, and the context and situatedness of his story. This allows for coding and analysis to take place that attends to the unique experiences of the participant as a whole rather than a part. Unlike another qualitative approach, such as phenomenology, the story is not distilled into its essence, but rather is kept whole for a more generalized 
understanding. This approach allows for an greater understanding of the participant's narrative by those who do not share the same experiences.

\section{Summary and Future Directions}

The landscape in most Western universities is changing. There are continually more international students and with them comes a greater need for faculty to better understand the student's experiences and ways of understanding and coming to knowledge. The rational cognitive driven model of one-size-fits-all education is no longer enough and is being challenged by these student's experiences. Add to this the increased interconnectedness of the global community and the world shrinks at an alarming rate. A theoretical framework that can assist others in better understanding non-Western ways of knowing is needed. This need comes from a research perspective to expand horizons into relatively unexplored facets of knowing. It also comes from the practical side of teaching in higher education to better understand students and break free from traditional Western approaches, which leave some students behind.

Embodied narrative knowing is in its infancy and is by no means complete. The current work that it is implemented in deals with the experiences of advanced martial artists and is attempting to bring these non-Western and other ways of knowing to a Western academic audience. The field of martial arts research potentially challenges the dominant social structure in Western society, positing the experiences learned through the body (not just about the body) as equally important to the experiences reflected through the mind. Kleinman (2005) summarizes this shared responsibility for meaning making as "wholeness" (Kleinman, 2005, p. 258). This concept requires us to be aware of the imposition of categories of "appropriate states of being" (p. 258) that separate ourselves from ourselves, removing ourselves from being whole.

\section{References}

Amann, T. L. (2003, October). Creating Space for Somatic Learning within Transformative Learning Theory. Presented at the Fifth International Transformative Learning Conference in New York, New York.

Berger, P. L., \& Luckmann, T. (1966). The social construction of reality. Garden City, New York: Doubleday

Brown, D., \& Johnson, A. (2000). The social practice of self-defense martial arts: Applications for physical education. Quest, 52, 246-259. doi: 10.1080/00336297.2000.10491713

Clandinin, D. J., \& Connelly, F. M. (2000). Narrative inquiry: Experience and story in qualitative research. San Francisco, California: Jossey-Bass. 
Crossley, N. (2007). Researching embodiment by way of 'body techniques'. The Author, $80-94$.

Flick, U. (2014). Approaches to qualitative research. In U. Flick (Eds.) An introduction to qualitative research (pp. 39-47). London, England: SAGE.

Flick, U. (2014). Theories underlying qualitative research. In U. Flick (Eds.) An introduction to qualitative research (pp. 75-94). London, England: SAGE.

Freiler, T. J. (2008). Learning through the body. New Directions for Adult and Continuing Education, 119, 37-47. doi: 10.1002/ace.304

Gergen, K. J. (1995). Social construction and the educational process. In L. P. Steffe \& J. Gale (Eds.), Constructivism in education (pp. 79-94). Hillsdale, New Jersey: Erlbaum.

Ghane, A., \& Sweeny, K. (2013). Embodied health: A guiding perspective for research in health psychology. Health Psychology Review, 7(1), 159-184.

Kleinman, S. (2005). The art of everything. Quest, 57, 255-261.

Kramp, M. K. (2004). Exploring life experience through narrative inquiry. In deMarrais, \& Lapan (Eds.), Foundations for research: Methods of inquiry in education and the social sciences (pp. 103-121). Mahwah, New Jersey: Lawrence Erlbaum Associates.

Lincoln, Y. S., Lynham, S. A., \& Guba, E. G. (2011). Paradigmatic controversies, contradictions, and emerging confluences, revisited. In N. Denzin, \& Y. Lincoln (Eds.), The Sage handbook of qualitative research (pp. 97-128). Thousand Oaks, California: SAGE.

Martínková, I., \& Parry, J. (2015). Martial categories: Clarification and classification. Journal of the Philosophy of Sport, doi: 10.1080/00948705.2015.1038829.

Merriam, S. B. (1995). What can you tell from an $\mathrm{N}$ of 1?: Issues of validity and reliability in qualitative research. PAACE Journal of Lifelong Learning, 4, 51-60.

Merriam, S. B., \& Associates. (2007). Non-Western perspectives on learning and knowing. Malabar, Florida: Krieger.

Merriam, S. B., \& Brockett, R. G. (2007). The profession and practice of adult education: An introduction. San Francisco, California: Jossey-Bass.

Michelson, E. (1998). Re-membering: The return of the body to experiential learning. Studies in Continuing Education, 20, 217-233. doi: 10.1080/0158037980200208

Polkinghorne, D. E. (1995). Narrative configuration in qualitative analysis. Qualitative Studies in Education, 8(1), 5-23.

Robert, D., \& Shenhav, S. (2014). Fundamental assumptions in narrative analysis: Mapping the field. The Qualitative Report, 19, 1-17.

Schutz, A. (1962). Collected papers, vol. 1. The Hague: Nijhoff.

Spector-Mersel, G. (2010). Narrative research. Narrative Inquiry, 20(1), 204-224.

Taylor, E. W. (1997). Building upon the theoretical debate: A critical review of the empirical studies of Mezirow's transformative learning theory. Adult Education Quarterly, 48 (1), 34-59. doi: 10.1177/074171369704800104 